Tropical Journal of Pharmaceutical Research December 2018; 17 (12): 2399-2404

ISSN: 1596-5996 (print); 1596-9827 (electronic)

(1) Pharmacotherapy Group, Faculty of Pharmacy, University of Benin, Benin City, 300001 Nigeria.

Available online at http://www.tjpr.org

Original Research Article

http://dx.doi.org/10.4314/tjpr.v17i12.13

\title{
Role of Notch signaling pathway in bone marrow mesenchymal stem cell therapy for phosgene inhalation- induced lung injury in rats
}

\author{
Yiru Shao ${ }^{1-3}$, Jie Shen ${ }^{1-3 \star}$, Fangqing Zhou ${ }^{1-3}$, Daikun $\mathrm{He}^{1-3}$ \\ ${ }^{1}$ Department of Intensive Care Unit, Center of Emergency \& Intensive Care Unit, ${ }^{2}$ Department of Intensive Care Unit, Medical \\ Research Center of Chemical Injury, ${ }^{3}$ Department of Intensive Care Unit, Medical Center of Radiation Injury, Jinshan Hospital, \\ Fudan University, Shanghai 201508, China
}

*For correspondence: Email: vq1300@163.com: Tel: +86-25-84175562

Sent for review: 28 September 2018

Revised accepted: 29 November 2018

\begin{abstract}
Purpose: To determining the expression and role of the Notch signaling pathway (NSP) in phosgene inhalation-induced lung injury in rats, and the therapeutic effect of bone marrow mesenchymal stem cell (MSC) on the lung lesions.

Methods: Wistar rats (220 - $280 \mathrm{~g})$ were randomly assigned to air inhalation group, phosgene inhalation group, and mesenchymal stem cell (MSC) intervention group. Each group had 8 rats. Directional flow phosgene inhalation device was used to produce phosgene inhalation-induced lung injury in the rats. Serum inflammatory cytokines (TNF- $\alpha, I L-8$ and IL-6) were determined using ELISA assay kits. The expressions of proteins related to the NSP (Notch1, Notch2, Hes1, Hes5) were quantified using Western blot.

Results: Phosgene inhalation brought about significant increase in TNF- $\alpha$, IL-8 and IL-6 levels ( $p<$ 0.01), but MSC intervention significantly reduced the expressions of these inflammatory factors to varying degrees $(p<0.05)$, although their levels were still significantly high, relative to the air inhalation group. Results from western blot showed that the Notch1, Notch2, Hes1 and Hes5 were upregulated in the phosgene inhalation group, when relative to the air inhalation group $(p<0.01)$. Protein expressions in the MSC intervention group were lower than those in the non-intervention groups $(p<0.05)$.

Conclusion: Phosgene inhalation activates Notch signaling pathway, while MSC intervention inhibits this signaling pathway. Thus, inhibition of NSP may be implicated in the protective effect of MSC therapy against phosgene-induced lung injury.
\end{abstract}

Keywords: Phosgene, Lung injury, Notch signalling pathway, Mesenchymal stem cells

\begin{abstract}
This is an Open Access article that uses a funding model which does not charge readers or their institutions for access and distributed under the terms of the Creative Commons Attribution License (http://creativecommons.org/licenses/by/4.0) and the Budapest Open Access Initiative (http://www.budapestopenaccessinitiative.org/read), which permit unrestricted use, distribution, and reproduction in any medium, provided the original work is properly credited.
\end{abstract}

Tropical Journal of Pharmaceutical Research is indexed by Science Citation Index (SciSearch), Scopus, International Pharmaceutical Abstract, Chemical Abstracts, Embase, Index Copernicus, EBSCO, African Index Medicus, JournalSeek, Journal Citation Reports/Science Edition, Directory of Open Access Journals (DOAJ), African Journal Online, Bioline International, Open-J-Gate and Pharmacy Abstracts

\section{INTRODUCTION}

Phosgene is widely used as an important chemical raw material [1-4]. The Shanghai Chemical Industry Park is one of China's largest investments. Bayer AG and BASF which operate in China account for approximately $65 \%$ of China's total consumption of phosgene. Although no serious public safety incidents have happened, phosgene poisoning is not uncommon 
and still poses a great threat. Phosgene inhalation-induced lung injury is a chemicallyinduced lung injury and a critically acute illness. About $30 \%$ of the lung injury patients suffer from acute respiratory distress symptom (ARDS), with mortality as high as $30-40 \%$. The hospital mentioned in this research is located in Shanghai Chemical Industry Park. It is responsible for studying the basis of phosgene inhalationmediated lung lesion, and for formulating appropriate treatment strategies. This is important for reducing mortality and improving treatment outcomes. Preliminary studies have shown that MSCs can alleviate phosgene inhalation-induced lung injury through a mechanism involving the regulation of inflammatory responses $[5,6]$. The specific targets of the MSCs therapy are the focus of these studies. The NSP plays an important role in lung injury repair by regulating the inflammatory responses [7]. This signaling pathway is related to the MSC therapy for other diseases $[8,9]$. However, not much is known about the role of the NSP in the MSC-mediated alleviation of phosgene inhalation-induced lung injury. The search for novel targets of MSC therapy is expected to increase understanding of the mechanism of the MSC therapy. The present study attempted to find potential targets of MSC therapy for phosgene inhalation-induced lung injury.

\section{EXPERIMENTAL}

\section{Reagents and equipment}

The reagents and equipment used were solid phosgene (Haining Zhonglian Chemical Co., Ltd); N, N-dimethylformamide (DMF, Sangon Biotech (Shanghai) Co., Ltd); rat ELISA kits (R\&D, USA); rat Notch1, Notch2, Hes1 and Hes5 antibodies (Santa Cruz, USA) and their corresponding secondary antibodies (Jackson, USA), Trizol reagent (Invitrogen, USA), and Coomassie brilliant blue staining kits (Shanghai USEN Biological Technology Co., Ltd). Others were Multisken Mk3 microplate reader (Thermo, USA); SZ61 optical microscope (Olympus, Japan); $\quad$ Molecular Imagerß Gel DocTM XR system 170-8170 (Bio-Rad, USA), and Power Pac200 electrophoresis system (Bio-Rad, USA). This study received approval from Jinshan Hospital Animal Ethical Committee (approval no. 2017-02912), and was carried out in line with the Principles of Laboratory Animal Care [10].

\section{Grouping and MSC intervention}

Twenty-four clean-grade Wistar rats (220 - 280 g) were used. Following a 7-day acclimatization to laboratory environment, they were assigned to three groups: air inhalation group, phosgene inhalation group and MSC intervention group (8 rats per group). Rats in the air inhalation group inhaled air, while those in the phosgene inhalation and MSC intervention groups inhaled an equivalent concentration of phosgene. The rats were fasted for $24 \mathrm{~h}$ before surgery, but allowed free access to water. In the MSC intervention group, MSCs $\left(0.5 \mathrm{~mL}, 2 \times 10^{6}\right.$ cells $/ \mathrm{mL}$ ) were injected via the tail vein immediately after phosgene inhalation.

\section{Rat model of phosgene inhalation-mediated lung lesion}

Directional flow phosgene inhalation device (provided by the Bayer Health \& Medical Care Research Center) was used to establish a rat model of phosgene inhalation-induced lung injury. The rats inhaled $8.33 \mathrm{mg} / \mathrm{L}$ of $100 \%$ pure phosgene for $5 \mathrm{~min}$, and they were sacrificed 24 $\mathrm{h}$ after the exposure. The tissues were harvested under intraperitoneal urethane anesthesia (0.2 $\mathrm{g} / \mathrm{mL})$.

Blood was collected from the femoral artery of each rat and allowed to stand for a while prior to centrifugation. The supernatant was collected. The rats were sacrificed by bloodletting through their femoral arteries. Lung tissues were harvested and processed into frozen sections which were fixed in methanol and stored in liquid nitrogen at $-80^{\circ} \mathrm{C}$.

\section{Isolation and culture of rat MSCs}

Using the same procedures for MSC isolation and culture in a preliminary study, MSCs were isolated from bone marrow by Ficoll density gradient centrifugation [5]. The cells were cultured in DMEM to the fourth generation. They were identified as CD34-/CD45-/CD90+ cells by flow cytometry, and shown to have osteogenic and adipose differentiation potential (high-purity MSCs).

\section{Histopathological examination of lung tissues}

Lung tissues were processed into conventional pathological sections and subjected to $\mathrm{H}$ \& $\mathrm{E}$ staining, followed by microscopic examination.

\section{Measurement of ratio of lung wet weight-to- dry weight}

The lung was excised from one side of each rat blotted out using filter paper. Wet weight was first determined, followed by determination of ratio of lung wet weight-to-dry weight. 


\section{Determination of serum II-6, TNF- $\alpha$ and IL-8}

Serum levels of IL-6, TNF- $\alpha$ and IL-8 were measured with ELISA assay kits in line with the kit protocol. Optical density readings were obtained in a microplate reader at $459 \mathrm{~nm}$, and a standard curve was plotted. The serum level of each factor was determined using a fully automated microplate reader.

\section{Expressions of Notch1, Notch2, Hes1 and Hes5 in lung tissues}

Protein expressions were determined by Western Blot. Total proteins were extracted from lung tissues and quantified. Then, $60 \mu \mathrm{g}$ of the protein was separated using SDS-PAGE. The resultant protein bands were transferred to polyvinylidene membranes and blocked using $5 \%$ defatted milk powder at room temperature. Notch1, Notch2, Hes1 and Hes5 primary antibodies (1:1000 dilution) were added dropwise and the membrane was incubated at $4{ }^{\circ} \mathrm{C}$ overnight. Thereafter, the corresponding secondary antibodies (1:2500 dilution) were added dropwise, followed by further incubation of the membrane at room temperature for $1 \mathrm{~h}$. The protein bands were visualized using enhanced chemiluminescence kit. Grayscale values of the bands were analyzed using a gel imager system. The housekeeping gene was GAPDH gene.

\section{Statistical analysis}

The results are presented as mean \pm SD. Intergroup comparisons were conducted using oneway ANOVA, while pairwise comparison was done with SNK method. All analyses were carried out with SPSS 13.0 software. Statistical significance was assumed at $p<0.05$.

\section{RESULTS}

\section{Histopathological changes in lung tissues}

Microscopic examination revealed that the alveolar spaces were intact in the control group. There was neither edema nor inflammatory change in the alveolar septa: the lung tissue structure was basically intact. However, after phosgene inhalation, the lung tissue structure became damaged: the alveolar space was impaired, and there were large amounts of exudate and hyaline membranes. Around the blood vessels there were numerous inflammatory cells and exudates, which caused apparent thickening of the alveolar space as well as bleeding and edema in lung parenchyma. Interestingly, MSC therapy resulted in significant

alleviation of the lung edema and exudate from alveolar space. The MSc treatment also reduced the number of inflammatory cells. Nonetheless, the damage to lung tissue structure in the MSC group was still more serious than that in the air inhalation group (Figure 1).

A

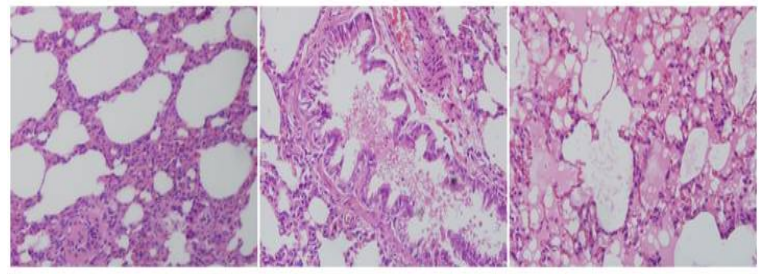

Figure 1: Pathological changes in lung tissues $(H \& E$, x400). A: Air inhalation group, B: MSC intervention group, C: Phosgene inhalation group

\section{Ratio of lung wet weight-to-dry weight}

The ratio of lung wet weight-to-dry weight was significantly higher in the phosgene inhalation group than in the air inhalation group $(p<0.01)$. However, this index was significantly lower in the MSC intervention group than in the phosgene inhalation group $(p<0.05)$. This indicated that phosgene inhalation aggravated pulmonary edema and that MSC intervention alleviated the resultant inflammatory responses, exudation and pulmonary edema (Table 1$)$.

Table 1: Lung wet weight-to-dry weight ratio (mean \pm $\mathrm{SD}, \mathrm{N}=8$ )

\begin{tabular}{lc}
\hline Group & $\begin{array}{c}\text { Ratio of wet weight-to- } \\
\text { dry weight }\end{array}$ \\
\hline Air inhalation & $3.74 \pm 0.82$ \\
Phosgene inhalation & $8.65 \pm 1.02^{\mathrm{a}}$ \\
MSCs intervention & $7.11 \pm 0.96^{\mathrm{b}}$ \\
\hline${ }^{\mathrm{a} P}<0.01$, compared with the air inhalation group; ${ }^{\mathrm{D}} p<$ \\
0.05, compared with the phosgene inhalation group. \\
Values are presented as mean $\pm \mathrm{SD}(\mathrm{N}=8)$
\end{tabular}

\section{Serum IL-6, TNF- $\alpha$ and IL-8}

The results on Table 2 reveals that the expressions of the inflammatory factors IL-8, TNF- $\alpha$, and IL- 6 were significantly upregulated in the phosgene inhalation group, when compared with the air inhalation group $(p<0.01)$. In contrast, the expressions of these inflammatory factors decreased to varying degrees after MSC intervention, with significant downregulation of IL6 and TNF- $\alpha(p<0.05)$. However, they were still higher than the corresponding levels in air inhalation group $(p<0.01)$. 
Table 2: Serum TNF-a, IL-6 and IL-8 levels (ng/ml)

\begin{tabular}{lccc}
\hline Group & TNF- $\alpha$ & IL-6 & IL-8 \\
\hline Air inhalation & $15.10 \pm$ & $17.53 \pm$ & $7.54 \pm$ \\
Phosgene & 2.65 & 3.33 & 0.32 \\
inhalation & $34.43 \pm$ & $46.39 \pm$ & $19.78 \pm$ \\
MSC & $4.09^{\mathrm{a}}$ & $5.11^{\mathrm{a}}$ & $3.65^{\mathrm{a}}$ \\
intervention & $30.44 \pm$ & $39.49 \pm$ & $18.62 \pm$ \\
\hline Values are presented as mean $\pm \mathrm{SD}(\mathrm{N}=8)$. $^{\mathrm{a}} p$ & $<$ \\
0.01, relative to air inhalation group; ${ }^{\mathrm{b}} p<0.05$, relative \\
to phosgene inhalation group
\end{tabular}

\section{Notch1, Notch2, Hes1 and Hes5 levels in lung tissues}

As shown in Figure 2 and Table 3, western blot results indicated significant upregulations of Notch1, Notch2, Hes1 and Hes5 in the phosgene inhalation group, relative to the air inhalation group ( $p<0.01$ ). Moreover, Notch1, Notch2, Hes1 and Hes5 expressions in the MSC intervention group were significantly lower than their expression levels before intervention $(p<$ $0.05)$, but were still higher than the corresponding expressions in the air inhalation group $(p<0.01)$.

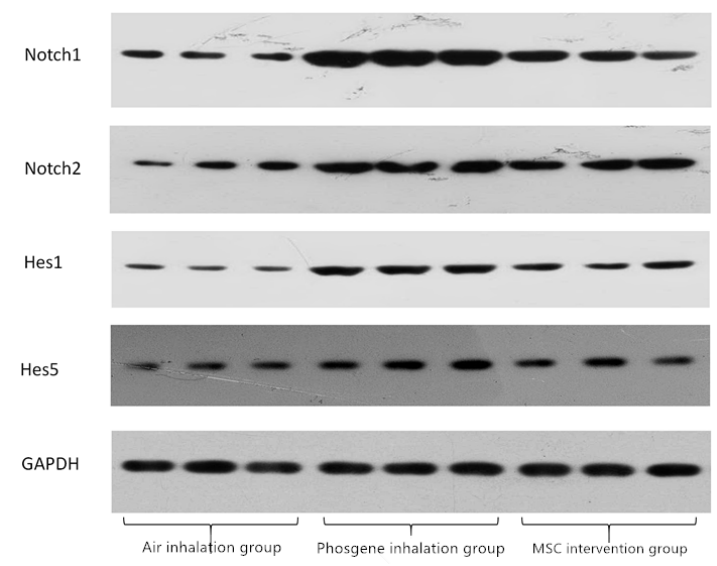

Figure 2: Western blot showing Notch-1 \& 2, and Hes1 \& 5 expressions in lung tissues

Table 3: Relative changes in expressions of Notch1, Notch2, Hes1 and Hes5 in lung tissues

\begin{tabular}{|c|c|c|c|c|}
\hline Group & Notch1 & Notch2 & Hes1 & Hes5 \\
\hline $\begin{array}{l}\text { Air } \\
\text { inhalation }\end{array}$ & $\begin{array}{c}0.42 \pm \\
0.03\end{array}$ & $\begin{array}{c}0.31 \pm \\
0.09\end{array}$ & $\begin{array}{c}0.26 \\
\pm \\
0.03\end{array}$ & $\begin{array}{c}0.33 \\
\pm \\
0.08\end{array}$ \\
\hline $\begin{array}{l}\text { Phosgene } \\
\text { inhalation }\end{array}$ & $\begin{array}{l}1.33 \pm \\
0.89^{\mathrm{a}}\end{array}$ & $\begin{array}{l}1.16 \pm \\
0.93^{\mathrm{a}}\end{array}$ & $\begin{array}{c}0.92 \\
\pm \\
0.16^{\mathrm{a}}\end{array}$ & $\begin{array}{c}0.49 \\
\pm \\
0.06^{a}\end{array}$ \\
\hline $\begin{array}{l}\text { MSC } \\
\text { intervention }\end{array}$ & $\begin{array}{l}0.97 \pm \\
0.18^{\mathrm{ab}}\end{array}$ & $\begin{array}{l}0.844^{\mathrm{ab}} \\
0.28^{\mathrm{ab}}\end{array}$ & $\begin{array}{c}0.48 \\
\pm \\
0.00^{\mathrm{ab}}\end{array}$ & $\begin{array}{c}0.40 \\
\pm^{ \pm} \\
0.01^{\mathrm{ab}}\end{array}$ \\
\hline
\end{tabular}

Values are presented as mean $\pm \mathrm{SD}(\mathrm{n}=8) ;{ }^{\mathrm{a}} p<0.01$, compared with the control group; ${ }^{b} p<0.05$, compared with the phosgene inhalation group

\section{DISCUSSION}

The use of stem cell therapy for lung injury has attracted a lot of attention. Bone marrow mesenchymal stem cells (MSCs) are easily available and suitable for in vitro culture. They also have the advantages of low immunogenicity, multi-lineage differentiation potential, induction of immunological tolerance and immunosuppression. In view of these characteristics, they are the optimal candidate cell materials for cell therapy and tissue engineering. MSCs enhance repair of lung injury by regulating inflammatory responses. Studies have shown that MSCs exert protective effects on the lungs by reducing plasma TNF-a and IL-6 levels in rats with endotoxin-induced lung injury, and by reducing lung wet weight-to-dry weight ratio and the activity of myeloperoxidase [11].

MSCs secrete soluble tumor necrosis factor receptor 1 (sTNFRI) and IL-I receptor antagonist through paracrine secretion, which completely antagonizes the pro-inflammatory effect of TNF and IL-1. This is considered as the mechanism involved in MSC-induced inhibition of inflammation. Studies have shown that MSC transplantation inhibited NF- $\mathrm{k} \beta$, and decreased the expressions of pro-inflammatory factors TNF$a$ and IL-6, while increasing the expression of anti-inflammatory factor IL-10. This agrees with previous findings in the rat model of phosgene inhalation-induced lung injury $[5,6]$.

The NSP is involved in many differentiation pathways of MSCs [12]. Widely present in animal cells, the NSP mediates cell differentiation, proliferation, apoptosis and inflammatory responses [13]. The Notch receptor is a singlepass transmembrane protein on the cell surface. It consists of extracellular domain and intracellular domain, the latter being composed of several structural domains. In mammals, there are four types of Notch receptor (Notch 1-4). When the receptor binds to the ligand, the intracellular part is hydrolyzed into soluble Notch receptor intracellular domain (NICD). The release of NICD is a rate-limiting process of the NSP. To date, only a few target genes of the NSP have been studies, and most of them are basic helix-loop-helix transcription factors (bHLH).

The NSP target genes identified in mammals are Hes genes (Hes-1 and Hes-5). The NSP participates in the repair of lung injury by regulating inflammatory responses [7]. The mechanisms include induction of the expressions of IL-6 and TNF- $\alpha$ to aggravate the inflammatory 
response; and regulation of lung injury by acting on the Toll-like receptors.

The present study has demonstrated that Notch1, Notch2, Hes1 and Hes5 proteins were all upregulated in lung tissues as a result of phosgene inhalation. In other words, all target proteins of the Notch signaling pathways were upregulated. Moreover, compared with the air inhalation group, lung injury was more severe in the phosgene inhalation group, presenting as typical pathological features of lung injury and increased lung wet weight-to-dry weight ratio.

Phosgene inhalation also caused elevation of IL6 , TNF- $\alpha$ and IL-8. This indicates that the severity of lung injury (inflammatory response, exudation and pulmonary edema) is closely related to the expressions of inflammatory factors and the NSP proteins. In phosgene inhalationinduced lung injury, NSP activation may induce inflammatory responses. In other words, the Notch signaling pathway is one of the signal transduction mechanisms that mediate phosgene inhalation-induced lung injury. This finding is consistent with the mechanisms of other factors that induce lung injury.

The results of this study also demonstrate that MSC intervention in a rat model of phosgene inhalation-mediated lung lesions provoked the downregulation of Notch1, Notch2, Hes1 and Hes5 proteins. The MSC intervention also alleviated lung injury to a certain extent, reduced lung wet weight-to-dry weight ratio, and downregulated the inflammatory factors TNF- $\alpha$, IL-8 and IL-6. Thus, MSC intervention may have a protective effect on lung injury, probably by inhibiting the expression of the Notch signaling pathway. In other words, MSCs can inhibit the Notch signaling pathway and offer protection against phosgene inhalation-induced lung injury.

Thus, MSC intervention for lung injury may work through the NSP. This inhibitory mechanism appears to be related to the expressions of IL-6 and TNF- $\alpha$, rather than the regulation of IL-8 expression. However, this study was unable to fully elucidate the mutual regulatory relationship among the three factors. This aspect will be addressed in subsequent studies with the use of specific Notch signaling pathway inhibitors or agonists.

\section{CONCLUSION}

NSP is activated in a rat model of phosgene exposure-related lung lesions. These can be mitigated by MSC intervention, the mechanism of which appears to involve Notch signaling pathway. This finding may lay the basis for the clinical application of MSCs for the treatment of phosgene inhalation-induced lung injury and other chemically-induced acute lung injuries.

\section{DECLARATIONS}

\section{Acknowledgement}

This work was funded by National Natural Science Foundation of China (81471850); This work was funded by the Jinshan District Health and Family Planning Commission-Training program for outstanding young people (no. JSYQ201602).

\section{Conflict of interest}

No conflict of interest is associated with this work.

\section{Contribution of authors}

This work was done by the authors named in this article. The authors accept all liability resulting from claims which relate to this article and its contents. The study was conceived and designed by Jie Shen; Fangqing Zhou, Daikun $\mathrm{He}$ collected and analysed the data; Yiru Shao wrote the text and all authors have read and approved the text prior to publication.

\section{REFERENCES}

1. Rendell R, Fairhall $S$, Graham $S$, Rutter $S$, Auton $P$, Smith $A$, Perrott $R$, Jugg B. Assessment of $N$ acetylcysteine as a therapy for phosgene-induced acute lung injury. Toxicol Lett 2018; 290(3): 145-152.

2. Yu JJ, Woong P, Tung N, Kyung PK, Heung YJ, Suhn HK, Wonhee S, Won K. COMP-angiopoietin-1 mitigates changes in lipid droplet size, macrophage infiltration of adipose tissue and renal inflammation in streptozotocininduced diabetic mice. Oncotarget 2017; 8(55): 9480594818.

3. Dai KHe, Yi RS, Lin Z, Jie S, Zhi YZ, Jing W, Guo XX. Adenovirus-delivered Angiopoietin 1 Suppresses NF-KB and p38 MAPK and Attenuates Inflammatory Responses in Phosgene-Induced Acute Lung Injury. Inhal Toxicol 2014; 26(3): 185-192.

4. Yun $P L$, Wen C, Ming YZ. Ulinastatin post-treatment attenuates lipopolysaccharide-induced acute lung injury in rats and human alveolar epithelial cells. Int $\mathrm{J} \mathrm{Mol} \mathrm{Med}$ 2017; 39(2): 297-306.

5. Jun FC, Yi RS, Guo XX, Chit CL, Jun L, Dao JX, Jie $S$. Bone marrow-derived mesenchymal stem cells attenuate phosgene-induced acute lung injury in rats. Inhal Toxicol 2015; 27(5): 254-261. 
6. Jing Z, Yiru S, Daikun H, Lin Z, Guoxiong X, Jie S. Evidence that bone marrow-derived mesenchymal stem cells reduce epithelial permeability following phosgeneinduced acute lung injury via activation of wnt3a proteininduced canonical wnt/B-catenin signaling. Inhal Toxicol 2016; 28(12): 572-579.

7. Hu X, Chung AY, Wu I, Foldi J, Chen J, Ji JD, Tateya T, Kang YJ, Han J, Gessler M, Kageyama R, Ivashkiv LB. Integrated regulation of Toll-like receptor responses by Notch and interferon-gamma pathways. Immunity 2008; 29: 691-703.

8. Kim DV, Jin HW, Song X, Xavier L, Eddy H, Ken M, Elke $D B$, Els VV, Karin $V$, Eline $M$ et al. Induction of miR146 a by multiple myeloma cells in mesenchymal stromal cells stimulates their pro-tumoral activity. Cancer Lett 2016; 377(1): 17-24.

9. Guillot L, Nathan N, Tabary O, Thouvenin G, Le Rouzic $P$, Corvol H, Amselem S, Clement A. Alveolar epithelial cells: master regulators of lung homeostasis. Int $J$ Biochem Cell Biol 2013; 45(11): 2568-2573.

10. World Health Organization. Principles of laboratory animal care. WHO Chron 1985; 39: 51-56.

11. Selvi G, Aytug A, Sakir NY, Ayse P, Mustafa Y, Melisa L, Gulhan $O$, Yalcin C. Mesenchymal stem cell treatment in hyperoxia-induced lung injury in newborn rats. Pediatr Int 2016; 58(3): 206-213.

12. Ye T, Ying $X$, Tai $Y X$, Long GC, Bin S, Bing S, Chao $X$, Massimo MM, Todd J, John VM, et al. Notch activation enhances mesenchymal stem cell sheet osteogenic potential by inhibition of cellular senescence. Cell Death Dis 2017; 8(2): 2595.

13. Li NX, Li NG, Xu FT, You WX, Yan Q, Lian HY, Xu H, Jin $Y P$. Effect of dioscin on promoting liver regeneration via activating Notch1/Jagged1 signal pathway. Phytomed 2018; 38: 107-117. 